\title{
A nova revolução copernicana: quando o Eu, o Outro e o Todo são outros*
}

Fecha de entrega: 7 de agosto de 2019

Fecha de evaluación: 7 de septiembre de 2019

Fecha de aprobación: 1 de diciembre de 2019

\author{
Luis Fellipe Garcia ${ }^{* *}$
}

\section{Resumo}

No prefácio da segunda edição da Crítica da razão pura, Kant propõe uma revolução metodológica em Filosofia similar à revolução copernicana: ao invés de tratar o observador como um centro fixo em torno do qual os objetos gravitam, pensá-lo antes como um móvel cujos movimentos cognitivos permitiriam explicar fenômenos anteriormente inexplicáveis. Alguns filósofos contemporâneos sugerem que essa revolução deva ser realizada de um ponto de vista geográfico, pois os problemas fundamentais da Filosofia parecem gravitar todos em torno do mesmo centro fixo, o qual não é confrontado à fragilidade de sua posição geográfica contingente, o centro europeu. $O$ objetivo deste artigo é reconstruir as linhas gerais dessa nova revolução copernicana como um procedimento de reavaliação de três vetores centrais do saber: o Eu, o Outro e o Todo.

Palavras-chave: eu, outro, todo, Filosofia decolonial.

* Pesquisa realizada na Universidade Federal de Minas Gerais (UFMG).

Citar como: Garcia, L. F. (2020). A nova revolução copernicana: quando o Eu, o Outro e o Todo são outros. Cuadernos de Filosofía Latinoamericana, 41(122), 17-38. Dol: https://doi.org/10.15332/25005375/5524

* Doutor em Filosofia pela Université Catholique de Louvain. Pesquisador de pós-doutorado da Fundação Alexander von Humboldt na Ludwig-Maximilians-Universität München.

E-mail: luisfellipegarcia@gmail.com 


\section{La nueva revolución copernicana: cuando el Yo, el Otro y el Todo son otros}

\section{Resumen}

En el prefacio de la segunda edición de Crítica de la razón pura, Kant plantea una revolución metodológica en Filosofía similar a la revolución copernicana: en vez de tratar el observador como un centro fijo en torno de quien los objetos gravitan, pensarlo antes como un móvil cuyos movimientos cognitivos permitirían explicar fenómenos anteriormente inexplicables. Algunos filósofos contemporáneos sugieren que esta revolución se debería realizar desde lo geográfico, pues los problemas fundamentales de la Filosofía parecen gravitar todos en torno del mismo centro fijo, el que no se confronta a la fragilidad de su ubicación geográfica contingente: el centro europeo. El artículo tiene como propósito reconstruir las líneas generales de esta nueva revolución copernicana como un procedimiento de reevaluación de tres vectores centrales del saber: el Yo, el Otro y el Todo.

Palabras clave: yo, otro, todo, filosofía decolonial.

\section{The New Copernican Revolution: When the I, the Other, and the Whole are All Another}

\section{Abstract}

In the preface to the second edition of the Critique of Pure Reason, Kant proposes a methodological revolution in philosophy similar to the Copernican Revolution: instead of treating the observer as a fixed center around which objects gravitate, it is rather conceived as a mobile whose movements would allow to explain a series of previously inexplicable phenomena. Some contemporary philosophers suggest that such a revolution should also be made from a geographic point of view, since the problems of Philosophy seem to gravitate always around the same fixed center, which is never confronted with the fragility of 
its contingent geographic position: the European center. The aim of this paper is to reconstruct the general lines of this new Copernican Revolution as a procedure to reevaluate the three main vectors of knowledge: the I, the Other, the Whole.

Keywords: I, other, whole, decolonial philosophy

"Desaprender 8 horas por dia ensina os princípios."

MANOEL De BARRos

\section{Introdução}

No prefácio da segunda edição de sua Crítica da razão pura, Kant propõe uma revolução metodológica em Filosofia: ao invés de tratar o observador como um centro fixo em torno do qual os objetos gravitam, pensá-lo antes como um móvel cujos movimentos cognitivos permitiriam explicar fenômenos anteriormente inexplicáveis. Essa mudança no método foi chamada por Kant de "revolução copernicana", pois ela implica que o homem, assim como o planeta, não seja mais compreendido como o centro para o qual o universo se desvela, mas antes como algo condicionado pela imperfeição de seus movimentos (Kant, KrV, xvi). A segurança do homem aristotélico-ptolomaico, que se sabe o centro do universo, é substituída assim pela fragilidade do homem copérnico-kantiano, que experimenta os limites de sua própria finitude. Bem entendido, a segurança é logo restabelecida pela dedução transcendental que dá ao sujeito a certeza de que, ainda que ele não seja o centro do universo, ele é, ao menos, o centro dos fenômenos cognitivos, à medida que é da articulação de sua sensibilidade, externa e interna, com suas categorias, que o conhecimento - de si, das coisas e do horizonte de articulação cognitiva do todo - torna-se possível.

Alguns filósofos contemporâneos sugerem que se essa revolução tenha sido efetiva de um ponto de vista cosmológico; ela parece não ter sido realizada de um ponto de vista geográfico, pois os problemas fundamentais da Filosofia parecem gravitar todos em torno do mesmo centro fixo, o qual não é confrontado à fragilidade de sua posição 
geográfica contingente: o centro europeu. Isso significa que o mundo cosmologicamente copernicano parece ser ainda um mundo geograficamente ptolomaico. Por conseguinte, o saber - de si, dos objetos e do todo - continua a ser estruturado em torno de um observador cujas estruturas de recepção e produção cognitiva talvez sejam mais frágeis e contingentes do que se crê. Diante desse estado de coisas, a Filosofia decolonial propõe uma nova revolução copernicana que visa deslocar geograficamente o centro epistêmico para tornar possível a apreensão e compreensão de fenômenos antes inexplicáveis ${ }^{1}$.

Antes de entrarmos nos detalhes desse deslocamento do centro epistêmico, façamos um breve esclarecimento introdutório sobre a expressão "Filosofia decolonial". Comecemos com o termo "decolonial" ou "descolonial”. O que isso significa? A partir do fim dos anos 1970, autores de origem asiática, como Edward Said e Gayatri Spivak, passaram a empregar ferramentas epistemológicas desenvolvidas pelo pós-modernismo para explorar problemas ligados à colonização da Ásia, intensificada sobretudo a partir do fim do século xviıI. Edward Said mostra como a dominação política daquela região se desdobra na formação progressiva de uma imagem exotizante do Oriente, oriunda de diversos tipos de documentos - relatos de viagens, cartas, aventuras romanceadas - que vão aos poucos se articulando em um processo de constituição de um novo objeto a ser institucionalizado através das lentes da Academia ocidental: o Oriente. O lugar politicamente dominado se consolida aos poucos como um objeto de estudos; objeto cujas múltiplas dimensões — artística, jurídica, epistêmica, religiosa, filosófica - são exploradas não enquanto questões artísticas, jurídicas, epistêmicas, religiosas ou filosóficas, mas enquanto questões orientais - e as questões orientais são formuladas pelas instituições de pesquisa ocidentais (Said, 1978). Alguns anos mais tarde, Gayatri Spivak mostra como esse tipo de problema tem desdobramentos políticos graves, à medida que vai se consolidando uma distinção entre os centros formuladores de problemas (produtores de conceitos) e os espaços cuja existência se reduz à objetividade a ser estudada, espaços povoados por seres humanos que podem ser estudados, pensados, falados, mas que não podem eles mesmos formular os problemas nos seus próprios termos, pensar e falar por si próprios - o que pode ser observado no título do famoso texto de Spivak (1988): “Can the subaltern speak?”.

1 A ideia de associar o pensamento decolonial a uma revolução copernicana vem de Enrique Dussel, um dos grandes nomes da Filosofia latino-americana; ele associa explicitamente o seu gesto de reconstrução da chegada dos europeus ao outro lado do Atlântico a partir da visão de mundo dos indigenas a "uma revolução copernicana da chave hermenêutica" (Dussel, 1993, pp. 71-114). 
A abordagem de Said e Spivak inaugura um horizonte de pesquisas que vai aos poucos encontrando eco no cenário internacional até se consolidar em torno da expressão “estudos pós-coloniais”, os quais, a exemplo da exploração pós-moderna dos efeitos políticos e epistêmicos das noções de universalidade e totalidade oriundas do modernismo, exploram os efeitos políticos e epistêmicos de um fenômeno contemporâneo ao modernismo: o colonialismo. Assim, do mesmo modo como se buscava lidar com os problemas político-epistêmicos do modernismo através de uma abordagem pós-moderna, busca-se, agora, lidar com os problemas político-epistêmicos do colonialismo através de uma abordagem pós-colonial.

Nos anos 1990, por ocasião do quinto centenário da chegada dos europeus à porção de terra que eles chamariam de "América”, autores latino-americanos como Enrique Dussel, Aníbal Quijano e, alguns anos depois, Walter Mignolo, deram início a uma exploração do significado e dos desdobramentos do acontecimento de 1492 - esse choque de cosmologias que marca o início do processo de formação da primeira imagem de um todo global, cujas partes serão articuladas não apenas nos primeiros mapas da orbe terrestre, mas ainda em um processo de articulação política, econômica e epistêmica que vai aos poucos conectando os acontecimentos de quatro continentes. As ferramentas elaboradas por Spivak e Said para analisar a articulação entre produção de conhecimento e poder imperial serão agora utilizadas para explorar o primeiro processo de globalização que vai generalizar práticas políticas - ao levar a visão europeia de Estado para as quatro partes do globo - e práticas epistêmicas - ao generalizar as visões europeias de espaço, tempo e linguagem para a orbe cujas primeiras imagens são desenhadas por cartógrafos europeus no século XVI.

O estudo dessa globalização política e epistêmica permite colocar em questão não apenas as marginalizações cognitivas oriundas da exotização da alteridade, mas ainda as marginalizações fundadas na universalização de uma estrutura básica de organização do saber, o que envolve, como mencionado, até mesmo as concepções de tempo, espaço e linguagem. Por isso, mesmo a abordagem em termos de pós-colonialismo é criticada por esses autores, na medida em que ela conteria ainda um aspecto de sucessão temporal entre a colonização e o que vem após (o colonial e o pós-colonial); ao invés disso, tais autores preferem trabalhar com o conceito de descolonização; uma descolonização das ferramentas conceituais básicas e, em geral, do nosso pensamento, o que permitiria, por um lado, provincializar o que se apresenta como um universal necessário e, por outro, reconstruir o poder conceitual das práticas cognitivas que foram marginalizadas 
por esse processo de universalização. Não se trata simplesmente de superar o período moderno e colonial dando um passo adiante para o pós-moderno e o pós-colonial; é preciso, sobretudo, fazer uma biópsia de nossos conceitos para identificar as estruturas de marginalização que se reproduzem sistemicamente no interior de nossos modos de abordar o real, o que inclui a própria concepção de tempo. É preciso, assim, descolonizar, isto é, diagnosticar e combater os efeitos da colonização que se reproduzem no nosso modo de ver nós mesmos, os outros e o mundo (o horizonte espaço-temporal). Por isso, descolonial ou decolonial, e não pós-colonial ${ }^{2}$.

Ainda, utilizamos a expressão "Filosofia decolonial", e não somente "estudos" ou "pensamento decolonial”, e esse emprego é proposital. Com efeito, parte do que está em questão aqui é justamente o que significa "Filosofia"; se a colonização tem um efeito duradouro sobre as estruturas mais básicas do saber e mesmo sobre as estruturas básicas da atribuição de significado (como a linguagem e as noções de espaço-tempo), e se a Filosofia é um estudo dessas estruturas mais fundamentais, então, o que está em questão aqui é também o que é a Filosofia. Ora, um estudo que busca: (1) mostrar que as estruturas básicas do saber e do real são particulares contingentes de um horizonte geocultural específico que se apresentam como universais necessários do todo global;

2 Há uma controvérsia na literatura em relação ao uso dos termos "decolonial" ou "descolonial". Paulo Margutti (2018), em um excelente artigo, faz uma reconstrução do debate e sugere que o termo "descolonial" seja mais adequado, já que "decolonial" é um anglicismo (formado a partir do prefixo inglês de- ao invés de des-), sendo oriundo assim de uma "tradução colonizada" (p. 236). Catherine Walsh (2009), por sua vez, sugere que "decolonial" sem o "s" seja um neologismo que visa marcar a distinção com descolonizar no sentido político clássico (pp. 14-15). De nossa parte, consideramos ambos os argumentos importantes: pois reconhecemos tanto a necessidade de não reproduzir um erro na tentativa de combatê-lo (levantar a bandeira da descolonização do pensamento a partir de uma tradução anglocêntrica) quanto 0 imperativo de um novo conceito pelo qual se busca iluminar os efeitos da colonização sobre a estrutura básica do saber. Mesmo reconhecendo a importância da crítica de Margutti, consideramos importante ressaltar que as discussões em torno dos principais conceitos do pensamento decolonial se articulam em um cenário internacional em que múltiplas tradições culturais dialogam (o que inclui ex-colônias lusófonas, hispanófonas, anglófonas, francófonas) e criam conceitos a partir de uma mistura de línguas: assim, o termo amplamente utilizado em inglês "coloniality", por exemplo, vem do termo cunhado por Anibal Quijano em espanhol "colonialidad", de modo que, no conceito "decolonialidade" (decolonialidad ou decoloniality), tem-se uma palavra construida a partir de um neologismo hispanófono (colonialidad) e de um prefixo anglófono (de-) - essa mistura de línguas não nos parece prejudicial; pelo contrário, cremos que ela é o efeito semiótico do fato de que os conceitos formulados no interior dessa tradição são fruto de uma circulação intercultural de ideias. Não evitaremos, assim, o uso do termo "decolonial" sem "s". Estamos, contudo, abertos a reavaliações futuras. 
e (2) mostrar que essas estruturas podem e devem ser repensadas em outros termos é um estudo filosófico, uma Filosofia ${ }^{3}$.

Pois bem, uma das estratégias fundamentais da Filosofia decolonial para diagnosticar e lidar com os efeitos da colonização sobre as estruturas básicas do ser e do saber é justamente aquilo que chamamos no início de "revolução copernicana", isto é, um deslocamento do eixo de articulação e formulação das questões filosóficas básicas a fim de, por um lado, (a) iluminar as contingências geográficas, políticas, econômicas e culturais envolvidas na formulação das questões básicas do ser e do saber e, por outro, (b) reconstruir alternativas conceituais que nos permitam ver com outros olhos histórias, acontecimentos, pensamentos e conceitos básicos, a partir de um outro centro. Trata-se, assim, de fazer uma nova revolução copernicana, pela qual o eurocentrismo ptolomaico será substituído aos poucos por uma perspectiva em que todas as partes do globo são igualmente provincianas e, nesse sentido, têm direitos iguais, diante de um sol que está alhures. O objetivo de nossa apresentação é reconstruir as linhas gerais dessa revolução copernicana como um procedimento de reavaliação de três vetores centrais do saber: o Eu, o Outro e o Todo.

\section{Eu: a invenção da identidade e sua relação com o poder}

No dia 12 de outubro de 1492, Cristóvão Colombo chega a uma ilha desconhecida do outro lado do Atlântico; ele navega por outras ilhas próximas e volta para a Espanha. Ao chegar de volta no continente europeu, ele escreve uma carta para o rei Fernando II, na qual ele diz que chegou às "Índias", onde encontrou ilhas "povoadas com gente sem número" e das quais "tomou posse". Na sequência da carta, diz Colombo sobre as ilhas povoadas que encontrou:

À primeira que encontrei, nomeei San Salvador em comemoração a Vossa Alta Majestade, ao qual maravilhosamente tudo isto se deve; os índios a chamam de Guanahaní; à segunda pus o nome de ilha de Santa Maria de Conceição; à

3 A palavra "pensamento" é certamente mais ampla e parece cobrir domínios da experiência humana mais amplos do que a palavra "filosofia"; optamos, contudo, juntamente com a tradição decolonial, por não abandonar o termo "filosofia", a fim de explicitar que parte do que está em questão no interior dessa tradição é uma reavaliação das fronteiras do conceito de filosofia. 
terceira, de Fernandina; à quarta, de Isabela; à quinta, de ilha Juana; e assim $a$ cada uma, um novo nome. [O grifo é nosso] (James, 1930, p. 2) ${ }^{4}$

Assim, Colombo inicia sua carta ao rei, anunciando um acontecimento e enumerando dois atos seus que ele considera que devem ser informados ao rei. $\mathrm{O}$ ato de tomar posse do território (um ato político) e o ato de nomear (um ato epistêmico). Essa passagem revela, de modo paradigmático, a dimensão das transformações por vir. A primeira ilha foi nomeada San Salvador, em homenagem à Sua Alteza, e ela se chama San Salvador até hoje; no dia anterior, ela se chamava, como diz Colombo, Guanahaní. A partir daquele dia, os humanos que ali viviam não seriam mais habitantes de Guanahaní, ao menos não oficialmente; eles continuariam sendo originários de Guanahaní no seu imaginário, mas, para efeitos práticos e políticos, um novo sistema de poder estava se instalando ali, um sistema a partir do qual aqueles seres que ali moravam passariam a ser referidos como san-salvadorenhos. Ademais, os humanos de Guanahaní, doravante para propósitos oficiais san-salvadorenhos, são também identificados por um outro nome utilizado por Colombo: índios. O povo que ali habitava é o povo dos taínos, uma tribo pacífica da região, hoje quase completamente extinta. Eles não eram índios ou indianos. Mesmo assim: os taínos são apreendidos por Colombo como habitantes do lugar em que ele pensava estar, ele pensava estar nas Índias, portanto eles são índios; na carta de Colombo assim, em menos de três linhas, os taínos de Guanahaní são transformados nos índios de San Salvador. Uma nova entidade que, no dia 11 de outubro de 1492, não existia, mas que passa a existir a partir do ato colombino de nomear.

Os taínos de Guanahaní, a partir daquele momento, ainda que eles não o soubessem, seriam progressivamente transformados nos habitantes de um novo mundo, de uma nova totalidade de sentido que estava sendo engendrada, um mundo no qual todo o seu entorno vai, aos poucos, se transformar; com efeito, além de terem sido transformados em índios, eles serão doravante habitantes de um mundo (1) apreendido no interior de um tempo linear segundo o qual aquele momento passará a ser referido como 1492 depois do nascimento de Jesus Cristo, ainda que eles desconhecessem completamente essa tradição; um mundo (2) no qual os taínos passarão a ser habitantes das Índias Ocidentais, ainda que eles estejam a leste, a oriente, da maior parte dos povos por eles conhecidos. Assim, a partir daquele momento, os taínos mudam de nome, mudam de tempo, mudam de espaço, mudam de sentido. Se o ato colombino de tomar posse

4 Carta de 15 de fevereiro de 1493. 0 original desta carta foi perdido, mas há várias versões conservadas em latim, espanhol e italiano. 0 texto aqui traduzido segue a edição de James (1930, vol. i, p. 2). 
daquelas terras seria eventualmente contestado e teria uma história de múltiplos conflitos cujo desfecho seria a independência política 300 anos mais tarde, resta que o ato colombino de nomear se consolidou - e os taínos de Guanahaní que viviam a leste e apreendiam o tempo de modo circular de acordo com suas próprias divindades são até hoje os índios de San Salvador que habitam no Ocidente no ano de 2020 depois de Jesus Cristo: um novo mundo estava sendo criado a partir do sistema semântico do qual Colombo era o vetor.

Mas isso não é tudo: no dia 23 de novembro de 1492, Colombo registra no seu diário o seguinte:

O Almirante navegou todo o dia para a terra, sempre para o sul. Sobre esse cabo se sobrepõe outra terra ou cabo, que também vai para o leste e que aqueles índios chamaram de Bohio. Diziam que era muito grande, que lá havia uma gente que tinha um olho na testa e outras [gentes] que eles chamavam de canibais, de quem demonstravam ter muito medo. (Colombo, 2001, p. 79)

Temos aqui a primeira ocorrência do termo "canibal" na tradição ocidental. Essa palavra não tem origem europeia e era usada pelos taínos para se referir a seus inimigos caribes. A palavra "canibal”, como sublinha Yobenj Chicangana-Bayona, vem de uma corruptela desse termo: caribe, caraíba, cariba, caniba, canibal (Chicangana-Bayona, 2009 , p. 15). Essa palavra anteriormente utilizada para designar um povo habitante de um espaço geográfico, os caribes, passa a ser utilizada progressivamente para designar uma prática específica, a antropofagia.

Quando a primeira coletânea de ilustrações daquelas terras surgiu em 1505, inspirada em uma carta apócrifa de Américo Vespúcio, ela foi intitulada Mundus novus; nela foi incluída a primeira imagem de canibalismo nesse espaço que, dali em diante, seria consistentemente chamado de "Novo mundo". Na imagem, vê-se um grupo de índios reunidos em torno de uma cabana; no centro da ilustração, há um corpo parcialmente desmembrado pendurado de uma corda e pendendo sobre uma fogueira; à esquerda desta, há um caldeirão, em torno do qual três mulheres estão reunidas, uma delas degusta um braço amputado, a outra segura uma perna desmembrada. Essa imagem teve um impacto fundamental sobre a apreensão dos habitantes daquelas terras no imaginário ocidental. A associação entre os habitantes do assim chamado "Mundus novus" e a prática do canibalismo será, a partir de então, uma constante. 
O nome artificial "índios" passa a ser assim associado à imagem do canibalismo em função das ilustrações do Mundus novus: um nome-imagem (índios-antropófagos) ao qual se atribuía uma posição geográfica (Novo mundo) ${ }^{5}$.

Ironicamente, a consequência dessa associação entre nome-imagem-posição (índiosantropofagia-Novo mundo) é que os taínos, inimigos dos caribes de quem eles temiam as práticas antropofágicas, seriam doravante associados ao nome índio, o qual é ele mesmo associado à imagem dos canibais do Novo mundo, de modo que os taínos, que não eram antropófagos, seriam eles mesmos associados à prática que eles temiam. Essa arapuca lógica que fez dos taínos praticantes de algo que eles temiam logo fará com que todos os habitantes daquelas terras fossem associados em bloco a essa mesma prática. Taínos, mapuches, astecas, incas, apaches, guaranis, maias, pouco importa que eles não sejam praticantes de antropofagia; eles (1) foram reunidos dentro de um mesmo "pacote identitário": índios; (2) esse pacote foi associado a uma imagem, a imagem de canibais, e (3) esta foi associada a uma posição no globo, a posição do assim chamado "Novo mundo", de agora em diante, todos eles são, em bloco, associados à mesma imagem. Uma falácia lógica começa a fazer história, uma falácia lógica começa a se converter em história ${ }^{6}$.

Quando, a partir de 1540, multiplicam-se as discussões sobre a legitimidade da conquista e a ocupação do novo território, essa falácia com seu nome, imagem e posição geográfica já estava consolidada e não se perguntava mais sobre a legitimidade de chamar todos aqueles habitantes daquela região pelo mesmo nome e associá-los em

5 Para uma rica reconstrução desse processo de gênese de uma imagem dos habitantes do novo mundo, ver a excelente obra de Chicangana-Bayona citada acima (2009). 0 autor faz uma reconstrução detalhada da consolidação progressiva de uma iconografia dos habitantes dessas terras a que os europeus chegaram em 1492 (pp. 19-94).

6 Cabe notar que não se trata de localizar o centro do problema na mera lógica, no sentido da lógica aristotélica ou da lógica proposicional. Ao contrário, o ponto é mostrar contingências históricas ligadas a transformações de relações sociais e de poder, as quais conduziram às navegações e fizeram com que um grupo de exploradores recém-chegados a terras anteriormente desconhecidas tivesse o poder de atribuir um nome aos habitantes daquelas regiões, associar a eles uma imagem e uma posição geográfica - essa capacidade de atribuir nome-imagem-posição se funda em uma posição de força; as consequências, contudo, desses mecanismos de generalização reproduzem o problema num nível epistêmico a tal ponto que ela oblitera as raízes contingentes do mecanismo lógico-semântico que ela põe em movimento. Em outras palavras, a posição de força da perspectiva europeia faz com que a associação índio-canibal-Novo mundo se consolide; uma vez consolidada essa associação, ela se reproduz por si mesma como silogismo lógico falacioso: (1) x é um taino; (2) todo taíno é índio; (3) todo índio é canibal; (4) logo x é canibal. As premissas ii e iii são falsas, mas elas se consolidam em função da posição de força do enunciador; uma vez tais premissas consolidadas, a falácia se reproduz por si mesma. 
bloco à mesma prática; a questão agora era outra, a saber: haveria legitimidade a invasão e conquista de um território chamado de "Novo mundo", povoado por habitantes chamados "índios", cujas práticas são marcadas pela antropofagia? A arapuca lógica estava estabelecida, e os taínos seriam dali em diante antropófagos do Novo mundo cujo destino seria julgado do outro lado do globo em função de uma prática que eles mesmos temiam.

Assim, quando em 1544, o sacerdote, filósofo e jurista espanhol Juan Ginés de Sepúlveda publica o diálogo Demócrates Segundo ou das causas da guerra justa contra os índios, o nome "índios" já tinha se firmado como o modo de designação de toda uma grande quantidade de povos associados à prática da antropofagia, e é contra esses povos reunidos sob esse conceito ficcional que ele pretende demonstrar que se poderia legitimamente fazer a guerra. Valendo-se da autoridade de Aristóteles, Sepúlveda argumenta que haveria uma diferença entre homens naturalmente aptos para mandar e homens que nasceram para servir, e que seria natural que estes últimos obedecessem aos primeiros para o bem de todos, pois “o perfeito deve dominar o imperfeito; o excelente, o seu contrário", e acrescenta que, se o imperfeito rejeita essa dominação, é legítimo submetê-lo pela força. Para provar que aqueles povos reunidos sob o pacote identitário "índios” deveriam ser submetidos à força, Sepúlveda afirma que dominá-los permitiria erradicar "as torpezas nefandas e o deplorável hábito de comer carne humana", além de abrir espaço para a pregação do Evangelho. O frei da ordem dos Dominicanos, Bartolomé de las Casas, ao tomar conhecimento da obra de Sepúlveda, tenta evitar que o rei conceda à obra o selo real, o que lhe conferiria legitimidade e um maior raio de circulação. As múltiplas discussões em torno da publicação do texto de Sepúlveda encontram seu desfecho na famosa discussão pública entre Sepúlveda e Las Casas convocada pelo Rei em 1550, e que entrou para a história como a "Controvérsia de Valladolid"?.

Na discussão, Sepúlveda retoma seus argumentos do livro: a guerra contra os índios é justa, pois (1) eles são bárbaros por natureza como o atesta a injúria da antropofagia e (2) a guerra facilitaria a pregação da fé cristã, a qual os libertaria da idolatria de suas crenças. Em sua resposta, Las Casas avança uma distinção entre diferentes tipos de barbárie: (1) povos de hábitos e costumes estranhos aos nossos; (2) ausência de escrita e (3) falta de capacidade de autogoverno. O bispo faz então uma descrição dos povos

7 Para uma boa reconstrução filosófica da controvérsia de Valladolid, ver Gutierrez (2007). 
indígenas (os quais ele conheceu bem por ter habitado muitos anos nas Américas) para mostrar que eles não são bárbaros no sentido 3, mas apenas no sentido 2 , de modo que não era legítimo fazer-lhes a guerra.

Em nenhum momento Las Casas coloca a barbárie do conceito fictício “índios” em questão, mas ele busca deslegitimar a associação entre barbárie e "escravidão por natureza”, feita por Sepúlveda ao mostrar que os assim chamados “índios” seriam apenas bárbaros iletrados. Nós temos aqui uma espécie de estrutura antinômica, no sentido kantiano, em que ambos os lados da oposição podem se revelar falsos quando se lhes expõe o pressuposto comum, a saber: o pressuposto de que todos os habitantes daquela região podem ser reunidos sob o mesmo pacote identitário e associados univocamente à mesma prática.

Os quatro lados da falácia identitária estão assim constituídos: (1) um nome fictício associado à (2) imagem de uma determinada prática e, a (3) uma posição geográfica, é atribuída (4) uma escala de valores hierárquica - são inferiores (bárbaros). A explicação da inferioridade vai certamente variar: a ausência de letras; a falta de capacidade de autogoverno; posteriormente, ela será associada ao clima, à cor da pele, à estrutura óssea - seja qual for a explicação buscada, a falácia está formada: um pacote identitário é associado a uma imagem, a uma posição geográfica e a uma hierarquia de valores. O mundo ptolomaico tem suas arapucas lógicas. Quando a colonização se intensificou, um novo grupo de seres humanos passou a ser transportado à força para as novas terras; ele foi igualmente associado a um nome (negros), a uma imagem e a uma escala de valores. Dentro desse mundo em formação em que o pacote identitário “índios" é associado à barbárie, o pacote identitário "negros" será associado à escravidão, ao passo que os recém-chegados ibéricos se estabelecerão como produtores de poder e de identidades. Consolida-se, assim, aos poucos, uma estrutura de distribuição de poder que se articula em torno das falácias identitárias do mundo de Colombo: tal articulação entre identidade e poder é o que Aníbal Quijano chamou de "colonialidade do poder"

8 A expressão "colonialidade do poder" é empregada por Quijano pela primeira vez em 1992 (Quijano, 1992) e, desde então, desenvolvida em um verdadeiro conceito em textos como "Colonialidad del poder: cultura y conocimiento en América Latina" (1998). A colonialidade do poder é uma articulação entre essas novas categorias identitárias surgidas no processo colonizador e a legitimação do exercício do poder. 


\section{O Outro: o problema do encobrimento}

O acontecimento de 1492 marca, como vimos, o início de um processo de globalização não apenas de modos de exercício do poder como também de modos de produção de significados. Se existe uma economia política por trás da exportação institucional iniciada em 1492, existe igualmente uma economia semântica por trás de uma exportação de modos de significar. Aqueles que vão aos poucos monopolizar a produção de instituições e de riquezas vão monopolizar igualmente a produção de sentido.

Os efeitos dessa globalização de um modo de produção de significado são analisados por Enrique Dussel em uma série de conferências ministradas em Frankfurt em 1992 por ocasião do quinto centenário da chegada dos europeus ao Novo mundo. O nome dessas conferências é simbólico: 1492: O encobrimento do Outro (1993). A tese central defendida por Dussel, como o nome já o indica, é que os povos que viviam nas terras alcançadas por Colombo em 1492 nunca foram descobertos, mas sim apreendidos sob um conjunto de conceitos do mundo dos colonizadores e, por conseguinte, encobertos na sua verdadeira alteridade. O Outro que ali estava foi encoberto por conceitos do mundo que ali chegavam com as caravelas: pensemos nos taínos de Guanahaní, encobertos sob a máscara "índios de San Salvador".

A fim de compreender verdadeiramente o que foi esse processo de encobrimento, é preciso colocar em questão esse mundo ptolomaico em que toda a produção de sentido, significado, identidades, diferenças, totalidades, se faz a partir do mesmo centro; é preciso desestabilizar esse centro, evidenciar sua contingência, sua fragilidade, suas limitações, mostrar como a pressuposição desse centro distorce fenômenos, torna-os dificilmente explicáveis; é preciso desconstruir o mundo ptolomaico, remetendo-o à sua própria contingência; é preciso uma revolução copernicana. Mas o que seria uma revolução copernicana nesse caso? Para Dussel, seria reconstruir o processo do choque entre o mundo de Colombo e o mundo dos locais, tanto da perspectiva de um como da perspectiva do outro. Trata-se, assim, de repensar o processo deslocando o centro produtor de significados de um mundo para outro, o que evidenciaria as múltiplas distorções oriundas da submissão semiótica de um mundo pelo outro.

Como vimos na primeira parte de nosso argumento, o mundo de Colombo opera como um centro produtor de significados que apreende os territórios explorados como um novo espaço no interior do qual ele atribui nomes, identidades, papéis, os quais se 
remetem uns aos outros dentro de um horizonte de significação que vai aos poucos surgindo como um Novo mundo composto por índios canibais; esse mundo é um mundo inventado como um anexo do centro de produção de significado do mundo ptolomaico de Colombo. Para os indígenas que ali estavam, esse processo é apreendido de outro modo, e o que a revolução copernicana busca fazer é justamente apreender esse outro modo ao inverter as posições do Eu e do Outro.

Se o primeiro momento da história que se inicia em 1492 ocorre no mundo de Colombo como um processo de construção de uma nova totalidade de sentido e, assim, de invenção de um novo mundo, esse processo é apreendido por algumas coletividades locais, como os astecas, por exemplo, como uma parusia, isto é, como o momento que marca a chegada de novos deuses ${ }^{9}$. Como se sabe a partir de diferentes fontes, muitas coletividades indígenas apreenderam os recém-chegados como deuses que, transportados em suas casas flutuantes (os navios), anunciavam o advento de uma nova era. Uma anedota de Lévi-Strauss ilustra bem esse ponto de Dussel: o antropólogo que viveu no Brasil por muitos anos conta que, se a grande dúvida dos ibéricos no seu primeiro contato com o indígena era examinar se eles tinham alma, uma pergunta oriunda da estrutura fundamental de atribuição de sentido do mundo medieval, a grande dúvida dos indígenas em relação aos recém-chegados era se eles tinham corpo, pois os recém-chegados foram apreendidos como deuses, de modo que não estava claro se eles eram ou não perecíveis (Lévi-Strauss, 1952) - além disso, como argumenta Eduardo Viveiros de Castro (2015), dentro da estrutura fundamental de atribuição de sentido daqueles povos, a alma é onipresente, de modo que não faria sentido perguntar se os recém-chegados tinham alma (pp. 25-26). Essa apreensão distinta explica por que, de um lado, o outro (do Eu ibérico) foi apreendido como um inferior cujo valor estava em xeque; ao passo que, do outro lado, o outro (do Eu indígena) foi apreendido como um divino cujo valor nunca esteve em questão. Duas estruturas de significação distintas, dois modos de apreensão da alteridade distintos.

A esse primeiro momento do desencontro de 1492, sucede o momento em que o mundo de Colombo se apreende como descobridor de um Novo mundo, o momento do descobrimento. O que o mundo de Colombo não percebe é que aquilo que está sendo descoberto como novo - o continente americano povoado por índios

9 Essa apreensão dos europeus no registro da parusia é reconstruída por Dussel (1993, pp. 119-131) a partir de uma análise das relações entre o governante da cidade de Tenochtitlán, Montezuma, e o conquistador espanhol Hernán de Cortés. 
canibais - é um mundo inventado; aquilo que o mundo de Colombo descobre é, na verdade, o modo como o próprio mundo de Colombo produziu uma totalidade de sentido que ele apreende como nova, e esse movimento de apreensão do produzido como novo marginaliza o previamente existente. O mundo de Colombo atua como uma espécie de idealismo berkeleyano avant la lettre, o que não era percebido antes de 1492 não existia, ao ser percebido em 1492 passa a existir como novo, como o inexistente que passou a existir, como um novo mundo a ser descoberto: em uma palavra, seré ser percebido, percebido pelo mundo de Colombo, percebido pelo mundo ptolomaico. Quando se inverte o centro a partir do qual a experiência se constrói, essa suposta descoberta é apreendida por diversos grupos locais como uma verdadeira invasão. Com efeito, os locais, ao perceberem que os recém-chegados não eram deuses e não tinham nenhum interesse por suas oferendas e cerimônias de boas-vindas, mas que buscavam antes escravizá-los e explorar suas terras, perceberam que os deuses das casas flutuantes eram humanos de armas fumegantes, e que a parusia divina era, na verdade, uma invasão humana.

A partir desse momento de revelação, ocorre uma guerra de conquista pela qual o mundo de Colombo vai entrar em conflito com os povos indígenas e buscar fazer valer a força material daquilo de que os indígenas não dispunham: ferro e cavalos. Os conflitos multiplicam-se, e os indígenas respondem à guerra de conquista pela organização de movimentos de resistência que se multiplicam entre povos como os incas, os astecas, os caribes, os taínos, os tupinambás e tantos outros. Ao tomarem consciência do processo de conquista, os povos locais organizaram a resistência com os meios de que dispunham.

Dada a superioridade material de um lado sobre o outro, o resultado do conflito era inevitável. E é a partir desse desfecho que se inicia o processo de colonização. Mas o que é a colonização? "Colonização" é um termo que deriva da palavra latina "colere”, que significa cultivar, semear, lavrar; por isso, o lavrador é também chamado de colono, aquele que cultiva a terra, que semeia, que lavra, que coloniza. Ora, aquilo que foi colonizado a partir da vitória de um mundo sobre o outro não foram simplesmente as terras que ali estavam, foram também os humanos, seus modos de organização social, de preservação da vida, de produção de sentido, seus modos de existir - o seu mundo da vida. Dussel emprega a expressão "mundo da vida" no sentido que foi usada por Edmund Husserl e que significa, grosso modo, o mundo pré-teórico no interior do qual as atribuições de sentido mais básicas são realizadas. 
Pensemos assim: todos nós nascemos e nos constituímos no interior de um espaço básico de atribuição de sentido; em casa, tomamos consciência aos poucos de um espaço composto por itens ligados aos alimentos (panelas, talheres, pratos, geladeira), itens ligados à limpeza (panos, rodo, vassoura, torneiras, chuveiro), itens ligados à imagem dos pais (lápis, papéis, canetas, instrumentos de trabalho); do mesmo modo, fora de casa, na escola, entra-se em contato com itens que adquirem sentido em função de outras atividades (salas de aula, cantinas, bibliotecas, locais de lazer). Esse espaço básico de atribuição de sentido diz respeito igualmente ao modo como tomamos consciência de nós mesmos, pois aprendemos a pensar em quem somos em função dos modos de existência que estão disponíveis no interior do nosso espaço de atribuição de sentido - ser trabalhador, ser estudante, ser ferreiro, carpinteiro, biólogo, engenheiro, mas também ser irmão, irmã, filha, filho, esposa, marido; todos esses são os modos de ser no interior do qual nós vamos aos poucos negociando a apreensão e determinação de quem somos.

Esse mundo de panelas, pratos, canetas, papéis, livros, cantinas, biólogos, carpinteiros, esposas, maridos, esse mundo é um mundo pré-teórico e é completamente distinto do mundo pré-teórico indígena - o mundo de panelas, livros, cantinas, esposas e engenheiros simplesmente não faz sentido no mundo pré-teórico indígena. No interior do mundo pré-teórico indígena, a consciência se constitui dentro de um espaço básico de atribuição de sentido constituído por rios, florestas, peixes, pássaros, animais ferozes, deuses, espíritos da floresta; espaço no interior do qual a própria subjetividade se constitui em função dos modos de existência disponíveis: ser guerreiro, ser xamã, ser caçador, ser cacique, ser cunhado, ser do mesmo clã; trata-se de um outro modo básico de atribuição de sentido. Pois bem, a colonização é um processo pelo qual um mundo pré-teórico vai sendo aos poucos controlado, dominado e, eventualmente, substituído pelo outro. $\mathrm{O}$ que se planta e se cultiva nesse processo não são apenas itens a serem consumidos, o que se planta ali são novos modos de ser, novos modos de viver e de reproduzir a existência. $\mathrm{O}$ que a colonização coloniza não é simplesmente a terra, mas o mundo da vida; e o que ela cultiva não são alimentos, mas subjetividades. Ela planta e colhe novos modos de ser sujeito, novos modos de ser.

Nesse quarto momento, a revolução copernicana nos permite ver que esse processo de cultivo de subjetividades pelo qual um novo mundo da vida se estabelece é igualmente um processo de destruição do mundo da vida precedente e, portanto, um processo que é apreendido da perspectiva de muitos dos povos locais como um processo apocalíptico, 
um processo pelo qual o mundo como totalização pré-teórica do sentido que existia ali anteriormente vai sendo desintegrado e destruído em função da marginalização dos locais de suas posições de produção de significado ${ }^{10}$. A vida, o mundo pré-teórico da vida, vai aos poucos perdendo sentido; não é uma surpresa que o suicídio coletivo seja até hoje uma prática comum entre os indígenas diante dos colonizadores do mundo da vida: colonização essa que nem sempre se percebe como tal, pois a contraparte da invenção da identidade é o encobrimento da alteridade.

\section{O Todo: a questão do lado oculto}

O processo de globalização do mundo pré-teórico é igualmente um processo de globalização do mundo teórico; a universalização de um modo de produção de sentido é, aliás, precisamente o que torna possível a universalização de um modo de compreensão do saber. Essa globalização de um modo de produção do saber é reconstruída por Walter Mignolo em seu livro O lado mais escuro do Renascimento, que explora justamente o lado oculto da primeira modernidade (1995). A tese fundamental de Mignolo é: (1) que o século xvi é o momento em que um modo paradigmático de apreensão dos três vetores fundamentais do conhecimento - a linguagem, o tempo e o espaço - é estabelecido e universalizado; e (2) que essa universalização faz com que compreensões alternativas desses três vetores e, portanto, compreensões alternativas do saber, sejam aos poucos obliteradas em um espaço de invisibilidade, em um lado oculto.

O lado oculto da primeira globalização é algo que, mais uma vez, só pode ser apreendido através de um movimento similar ao que Dussel chamou de revolução copernicana, pois é apenas quando se adota o ponto de vista dos povos que não ocupam a posição de centro produtor de sentido que se apreende a dimensão dos efeitos dessa globalização de uma compreensão determinada da linguagem, do tempo e do espaço. E essa é precisamente a estratégia de Mignolo, que, ao invés de examinar as diferentes concepções de linguagem no interior do espaço europeu no século XVI (abordagem ptolomaica), vai explorar o uso que foi feito das gramáticas (e assim de uma concepção da linguagem) no processo colonizador (deslocamento do centro de análise).

10 Pode-se falar aqui em uma espécie de expropriação das posições de produção de sentido, o que sublinha simultaneamente o débito e a originalidade de Dussel em relação aos trabalhos de Karl Marx. Por um lado, trata-se de compreender um mecanismo de totalização que gera sistematicamente exclusões como faz o autor alemão em sua análise da gênese do Capital; por outro lado, esse mecanismo de totalização operante no nível econômico opera igualmente no nível semântico, pois, no caso da colonização, não se trata apenas de uma exclusão econômica, mas também de uma exclusão epistêmica. 
Esse deslocamento é o que permite a Mignolo identificar, nas primeiras gramáticas vernáculas de língua espanhola publicadas no fim do século XV e no início do século XVI, a clara consciência de que a língua escrita é o veículo de expressão da lei, e que o ensino da gramática é o ensino do instrumento pelo qual os novos povos conquistados podem entender a lei a ser instaurada. Em outras palavras, existe uma relação constitutiva entre a linguagem escrita e o estabelecimento da lei. A partir dessa constatação, o autor argentino argumenta que o século XVI foi, em função da intensificação do processo colonizador, um período marcado pela exportação de instituições jurídicas através da palavra escrita; esse processo foi acompanhado por um processo de exportação da religião do Livro (Bíblia), na qual a palavra escrita funciona igualmente como o vetor da lei divina. Esse movimento, que faz da palavra escrita o vetor de exportação da lei humana e da lei divina, é o motor do estabelecimento progressivo de uma Filosofia da linguagem que prioriza a escrita sobre a fala.

Tal processo conduz a uma canonização do livro, que passa a ser compreendido como o depositário por excelência da verdade, o que conduz à consolidação de uma determinada concepção de escritura que prioriza a escrita alfabética, em detrimento de outras compreensões alternativas (como os ideogramas, a pintura, os quipus incas - um conjunto de cordas de algodão cuja disposição permite a preservação e transmissão de histórias). Do mesmo modo, isso faz com que a leitura seja apreendida como uma decifração de palavras por oposição a compreensões alternativas da leitura, como a decodificação de imagens ou de acontecimentos no mundo (ler um acontecimento, ler as estrelas etc.). Em função desse processo, consolida-se aos poucos uma imagem do conhecimento e da verdade que é intrinsecamente conectada ao livro e à letra escrita. Essa concepção da linguagem tem, por efeito colateral, a formação de hierarquias cognitivas em que o saber de um povo vai ser avaliado por sua capacidade de manejar o sistema de signos priorizados pelo mundo de Colombo. Assim, a globalização de um modelo de concepção da linguagem oriundo do mundo judaico-cristão tem efeitos sobre o modo como outros povos são vistos e apreendidos do ponto de vista cognitivo ${ }^{11}$.

Essa priorização da escrita sobre a fala tem por consequência a compreensão da preservação e registro da memória como algo constitutivamente ligado à letra escrita. A associação entre registro da memória e escrita conduz à consolidação progressiva de

11 Essa reconstrução da consolidação de uma Filosofia da linguagem no interior da qual a escrita adquire uma prioridade sobre a fala é feita por Mignolo na primeira parte de seu livro, intitulada "A colonização das línguas". 
uma imagem da história como algo que depende fundamentalmente da escrita. Isso faz com que o relato aceito como relato fidedigno dos povos sem escrita alfabética seja um relato que deve necessariamente ser produzido por povos com escrita alfabética. Em outras palavras, a memória e história desses povos será doravante registrada e contada por aqueles que dispõem do sistema alfabético, e que se tornarão assim os porta-vozes da história e do sentido dos acontecimentos e das memórias de outros povos.

Isso significa que as memórias dos povos sem escrita alfabética se converterão em um acontecimento no imaginário de outro povo, de modo que eles mesmos serão aos poucos convertidos em personagens de uma outra memória. Os dados mnemônicos daquilo que foi chamado de "Novo mundo" serão doravante apreendidos e organizados dentro do sistema mnemônico do mundo que produziu aquele espaço como um horizonte de significação novo. Esses dados mnemônicos do Novo mundo só adquirem sua consistência epistêmica, suas múltiplas remissões de sentido que fazem com que aquele espaço seja semanticamente consistente e possa produzir seus discursos com pretensão de verdade, a partir do espaço epistemológico do colonizador. A expropriação do sentido conduz, naturalmente, à expropriação das possibilidades de dizer a verdade; a verdade do mundo indígena passará a ser apreendida como algo que só se desvela no interior do modo europeu de apreensão e organização dos dados mnemônicos. A globalização de um modo de lidar com a memória gera, assim, a marginalização de outros modos de produção da história e da verdade ${ }^{12}$.

Finalmente, consolida-se, igualmente no século Xvi, um modo determinado de apreensão do espaço em relação direta com o modo como o mundo de Colombo vai construir os primeiros mapas. A construção dos mapas envolve um aprimoramento do instrumental geométrico de representação do globo. Esse processo vai conduzir, segundo Mignolo, a uma priorização progressiva do espaço geométrico sobre algo que poderia ser designado como espaço existencial - isto é, não um espaço apreendido como a forma da exterioridade estudada pela geometria, mas o espaço cujos traços fundamentais são o lugar e suas múltiplas relações com a proximidade e a distância.

Essa concepção do espaço como um lugar a partir do qual o perto e o longe são concebidos é o que permite compreender, sugere Mignolo, as múltiplas incompreensões entre o missionário cristão Matteo Ricci e os mandarins chineses a quem ele apresentou

12 Esses efeitos da colonização das línguas sobre os modos de apreensão do tempo são reconstruídos por Mignolo na segunda parte de seu livro intitulada "A colonização da memória". 
em 1570, em sua expedição à China, um dos primeiros mapas do globo terrestre ${ }^{13}$. Os mandarins chineses não podiam aceitar aquele mapa que marginalizava a China no canto superior direito do globo, afastada do centro que é onde ela deveria estar. Se Ricci toma essa resistência como um sinal do etnocentrismo chinês, o que ele não percebe é que o seu próprio mapa é igualmente um exemplo de um mapa cujo centro é estabelecido em função das contingências históricas e culturais do povo que produziu aquele mapa - o povo que pôs o mundo de Colombo no centro ${ }^{14}$.

A priorização do espaço geométrico sobre o espaço existencial contribui para a obliteração do conjunto de decisões políticas, históricas e culturais que estão por trás da construção do espaço a partir daquele centro específico, em relação ao qual todos os demais espaços serão posicionados. Esse processo de obliteração das contingências por trás da representação do espaço contribui igualmente para a naturalização de outras contingências, como, por exemplo, a associação das terras exploradas por Colombo à imagem do Novo mundo, apreendido, desde as primeiras cartas cosmográficas da orbe, como quarta parte do globo. Essas designações temporais "novo" e "quarta parte" (quarta parte a ser "descoberta”) manifestam, aliás, algo que já estava latente na construção de uma narrativa mnemônica unificada a partir do mesmo sistema de organização da memória oriundo do mesmo centro de produção de sentido: a apreensão dos diferentes espaços como distintas manifestações temporais. Com efeito, o que torna possível a apreensão daquele espaço explorado por Colombo como o espaço do Novo mundo, ou da quarta parte do globo, é o sistema referencial no interior do qual diferentes dados espaciais são organizados no interior de um mesmo sistema temporal, sistema esse que é apreendido, em função da tradição judaico-cristã como um sistema linear (que conduz da criação ao juízo final); a partir desse sistema, as diferenças espaciais serão apreendidas como manifestações do atraso ou do avanço, como manifestações espaciais do tempo linear.

Assim, uma Filosofia da linguagem que eleva a grafia acima da oralidade tem um efeito fundamental sobre a compreensão da escrita do tempo (historiografia) e da escrita do espaço (cosmografia) - o que impacta, por sua vez, a formação progressiva de um processo de totalização espacial, temporal e semântico; processo pelo qual surge, aos

13 Para uma reconstrução completa desse episódio, ver Mignolo (1995, pp. 219-226).

14 Os desdobramentos da nova concepção de linguagem em relação ao espaço são explorados por Mignolo na terceira e última parte do livro intitulada "A colonização do espaço". 
poucos, um lado oculto oriundo dos múltiplos efeitos de marginalização cognitiva pelos quais o espaço, o tempo e o sentido de tantos mundos vai sendo ocultado. $A$ nova revolução copernicana é uma estratégia para tentar recuperar esses sentidos e, em geral, para tentar recuperar nosso sentido.

\section{Conclusão}

A revolução copernicana proposta pela Filosofia decolonial permite, assim, iluminar o processo de globalização da produção do significado, a globalização de um mundo pré-teórico, em que (1) se articulam identidade e poder (colonialidade do poder) e cuja contraparte é um (2) uma obliteração progressiva da alteridade (encobrimento do outro); essa globalização do mundo pré-teórico $(1+2)$ torna possível (3) a globalização de um mundo teórico fundado em uma compreensão específica dos vetores fundamentais do saber cuja universalização engendra uma dimensão oculta da totalidade espacial, temporal e semântica visível (lado oculto). A revolução copernicana nos permite ver os mundos em que o eu produtor de significados, o outro instigador da produção e o todo engendrado são outros. Seu objetivo é permitir que adotemos perspectivas capazes de deslocar o centro produtor de significados e explorar os efeitos de tais deslocamentos sobre o horizonte de constituição de sentido. Tal deslocamento permite colocar em questão não apenas generalizações falaciosas como "índios", “canibais" ou "bárbaros", como ainda questionar todo o sistema de produção de sentidos, o que inclui as noções de espaço, tempo e mesmo as categorias mais básicas do saber, como mostrou recentemente Eduardo Viveiros de Castro em suas Metafísicas canibais. A contribuição da nova revolução copernicana é mostrar que assim como o homem não é o centro cosmológico do universo, tampouco o Ocidente é o centro epistêmico do saber, pois, diante do sol que está alhures, somos todos igualmente pequenos e igualmente grandes.

\section{Referências}

Chicangana-Bayona, Y. (2009). Imagens de canibais e selvagens do novo mundo: do maravilhoso medieval ao exótico colonial (séculos XV-XVII) (Marcia Aguilar Coelho, trad.). Campinas, Brasil: Editora Unicamp.

Colombo, C. (2001). Diários da descoberta da América: as quatro viagens e o testamento. Porto Alegre: L\&PM. 
Dussel, E. (1993). 1492: O encobrimento do Outro. A origem do mito da modernidade (Jaime Classen, trad.). São Paulo, Brasil: Vozes.

Gutierrez, J. L. (2007). Aristóteles em Valladolid. São Paulo: Editora Mackenzie.

James, L. C. (1930). Selected Documents Illustrating the four Voyages of Columbus. England: The Hakluyt Society.

Kant, I. (2001). Crítica da razão pura (Manuela dos Santos e Alexandre Morujão, trads.). Lisboa: Fundação Calouste Gulbenkian.

Lévi-Strauss, C. (1987 [1952]). Race et histoire. Paris: Editions Gallimard, Folio Essais. Margutti, P. (2018). Filosofia e pensamento descolonial. Sapere Aude, 9(18), 223-239. Mignolo, W. (1995). The Darker Side of the Rennaissance. Litteracy, Terrioriality and Colonization. Michigan: University of Michigan Press.

Quijano, A. (1992). Colonialidad y Modernidad/Racionalidad. Peru Indígena, 13(29), 11-20.

Quijano, A. (1998). Colonialidad del poder: cultura y conocimiento en América Latina. Ecuador Debate, 44, 227-238.

Said, E. (1978). Orientalism. New York: Pantheon.

Spivak, G. (1988). Can the subaltern speak? Em C. Nelson e L. Grossberg (eds.), Marxism and the Interpretation of Culture Urbana (pp. 271-313). Illinois: University of Illinois Press.

Viveiros de Castro, E. (2015). Metafísicas canibais. São Paulo: N-1 edições.

Walsh, C. (2009). Interculturalidad, estado, sociedad: luchas (de)coloniales de nuestra época. Quito: Universidad Andina Simón Bolívar/Ediciones Abya-Yala.

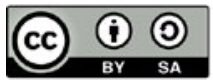

